\title{
Chronic Administration of Quercetin Induces Biomechanical and Pharmacological Remodeling in the Rat Coronary Arteries
}

\author{
A. MONORI-KISS ${ }^{1}$, F. KISS ${ }^{1}$, J. M. RESTIFO ${ }^{1,2}$, E. MONOS ${ }^{1}$, G. L. NADASY ${ }^{3}$ \\ ${ }^{1}$ Institute of Clinical Experimental Research, Semmelweis University, Budapest, Hungary, ${ }^{2}$ Faculty \\ of Pharmacy, University of Palermo, Palermo, Italy, ${ }^{3}$ Department of Physiology, Semmelweis \\ University, Budapest, Hungary
}

Received May 31, 2016

Accepted January 12, 2017

On-line April 12, 2017

\section{Summary}

Acute dilation brought about by the dietary flavonoid quercetin in coronary arterioles has been described earlier, but no information is available on its chronic effects. Male Wistar rats (body weight about $190 \mathrm{~g}$ ) were divided to two groups: the quercetin-treated group $(n=22)$ had quercetin supplementation of approximately $30 \mathrm{mg} / \mathrm{kg} /$ day, whereas the control group $(n=20)$ had none. After eight weeks of treatment, intramural coronary arterioles with identical passive diameters $(178 \pm 14 \mu \mathrm{m}$ and $171 \pm 9 \mu \mathrm{m})$ were prepared and their biomechanics and pharmacological reactivities were tested using pressure arteriography ex vivo. The spontaneous tone of quercetin-treated arteries was higher $(16.5 \pm 1.9 \%$ vs. $12.9 \pm 0.9 \%)$, which resulted in a reduced lumen size $(144 \pm 9 \mu \mathrm{m}$ vs. $167 \pm 12 \mu \mathrm{m})$, thicker vascular wall $(22.6 \pm 1.8 \mu \mathrm{m}$ vs. $17.4 \pm 1.6 \mu \mathrm{m})$ and decreased tangential wall stress $(16.8 \pm 1.1 \mathrm{kPa}$ vs. $20.5 \pm 1.6 \mathrm{kPa})$ in supplemented animals (in spontaneous tone at $50 \mathrm{~mm} \mathrm{Hg}, \mathrm{p}<0.01$ in all these comparisons). Elevated basal NO release resulted in increased endothelial dilation in quercetin-treated animals, especially at higher intraluminal pressures $(10.8 \pm 2.5 \%$ vs. $5.7 \pm 1.3 \%$ at $70 \mathrm{~mm} \mathrm{Hg}, p<0.01$ ). We found remodeling of the geometry of coronary arterioles to ensure higher dilatory reserve and nitrogen monoxide production, as well as lowered elastic stress of the vessel wall.

\section{Key words}

Quercetin - Vascular remodeling - Coronary circulation • Arterioles • Endothelial nitric oxide synthase

\section{Corresponding author}

A. Monori-Kiss, Institute of Clinical Experimental Research, Semmelweis University, Túzoltó Str 37-47, H-1094 Budapest, Hungary. Fax: + (36 1) 3343162. E-mail: monorikiss.anna@ med.semmelweis-univ.hu

\section{Introduction}

Dietary polyphenols are present in a mixed human diet in remarkable amounts, around $1 \mathrm{~g} /$ day. They are represented by diverse molecules, quercetin being one of the most frequent components among them (28-42 mg/day) (Edwards et al. 2007, Scalbert and Williamson 2000). This amount has cardioprotective, antihypertensive (Larson et al. 2012), antioxidant (Galisteo et al. 2004) and antilipemic (Lee et al. 2011) effects. Proper functioning of coronary resistance arteries is a key condition to supply the myocardium with oxygen and nutrients. Although the acute dilating effect of quercetin on major and resistance-sized vessels including coronary resistance arteries has been proven earlier (Ibarra et al. 2003, Monori-Kiss et al. 2014), much less is known about the chronic effects of quercetin on resistance arteries. No publication deals with coronary resistance arteries in this respect, despite the accepted view that quercetin is a potent preventive and therapeutic substance for several forms of cardiovascular disease, including cardiac hypertrophy (Yan et al. 2013, Han et al. 2009). Targeted chronic remodeling studies on large arteries have shown decreased neointima formation and decreased collagen deposition in the abdominal aorta (Huang et al. 2009) as well as decreased collagen I 
and III expression in myocardial tissue (Yan et al. 2013). These results raise the possibility but do not prove that chronic quercetin supplementation might also favorably affect the biomechanical properties of resistance-sized arteries. Whereas there are several differences between human and rodent metabolism, oral administration of quercetin to rodents seems to be a good model for polyphenol-rich food in humans (Kawai et al. 2009).

The aim of this study was to examine the longterm effects of a realistic dose of the flavonoid quercetin on the segmental remodeling of biomechanical and pharmacological properties of coronary arterioles compared to those from untreated normal control rats kept in parallel. It is hypothesized that long-term quercetin-treatment enhances basal NO-mediated dilation, limits dilation to norepinephrine and improves adaptive function of smooth muscle.

\section{Materials and Methods}

\section{Animal treatment and preparation of the segments}

All procedures conformed to the Guide for the Care and Use of Laboratory Animals (Guide for the care and use of the laboratory animals, $8^{\text {th }}$ edition, ELAR/NRC 2011), the legal and institutional guidelines for animal care and were approved by the Animal Care Committee of the Semmelweis University and Hungarian authorities (22.1/2960/003/2009). Male Wistar rats at the age of approximately 2 months (180-200 g body weight) were randomly distributed to two groups. All animals had the same rat chow ad libitum (S8106-S011 SM, Ssniff Spezialdiaten, Soest, Germany). The quercetin-treated group ( $\mathrm{n}=22)$ had this standard rat chow and a suspension of quercetin, $0.3 \mathrm{~g} / 1$ suspended in tap water, to drink ad libitum. After sterilization in autoclave the chow is almost quercetin-free (Yoo et al. 2012). Based on an average of $100 \mathrm{ml}$ pro $\mathrm{kg}$ body weight water consumption (Wade et al. 2002), this treatment means approximately $30 \mathrm{mg} / \mathrm{kg}$ body weight of quercetin supplementation pro day. Considering the higher metabolic rate per $\mathrm{kg}$ body weight of rats, this dose is comparable with $5 \mathrm{mg} / \mathrm{kg} /$ day human dose (Reagan-Shaw et al. 2008). A suspension of this concentration was prepared of quercetin hydrate (IUPAC name of quercetin: 2-(3,4-dihydroxyphenyl)-3,5,7-trihydroxy-4H-chromen4-one, purity $\geq 95 \%$ measured by HPLC analysis performed by manufacturer) without any excipient. Suspensions proved to be stable. To prevent oxidation, the suspension was freshly prepared on every second day. The control group $(n=20)$ was kept in parallel (at the same temperature and room) on the same common chow but provided with tap water (vehicle of the suspension) without any supplementation. The animals' weight, turgor of the skin and behavior were checked twice a week.

After 8 weeks of treatment, rats were anesthetized with pentobarbital (Nembutal, Ceva Santé Animale, Libourne, France, $45 \mathrm{mg} / \mathrm{kg}$ body weight i.p.). The heart was removed, its weight was measured, and was next put in cold oxygenized Krebs-Ringer solution (composition in mmol/l: $\mathrm{NaCl} 119, \quad \mathrm{KCl} 4.7$, $\mathrm{NaH}_{2} \mathrm{PO}_{4} 1.2, \quad \mathrm{MgSO}_{4} 1.17, \quad \mathrm{NaHCO}_{3} 24, \mathrm{CaCl}_{2} 2.5$, glucose 5.5, and EDTA 0.034). A small intramural coronary arteriole with an outer diameter between 150-200 $\mu \mathrm{m}$ was prepared in situ from a terminal branch of the left anterior descendent coronary artery, as described earlier (Nadasy et al. 2001). The excised vessel segments had more than $2.0 \mathrm{~mm}$ length to maintain the physiological cylindrical shape. They were cannulated at both ends using microcannulas with outer diameters around $130 \mu \mathrm{m}$, and mounted in a glass-bottomed organ bath (Experimetria LTD, Budapest, Hungary), then axially extended by $10 \%$, to simulate the in vivo axial extension ratio. Artery segments were pressurized intraluminally by servo-controlled pumps (Living Systems, Burlington VT, USA). The bath was thermostated at $37^{\circ} \mathrm{C}$, and bubbled with a gas mixture of $5 \% \mathrm{CO}_{2}, 20 \% \mathrm{O}_{2}$ and $75 \%$ of $\mathrm{N}_{2}$, keeping the $\mathrm{pH}$ at 7.4 . During incubation, continuous superfusion was ensured at a rate of $2.8 \mathrm{ml} / \mathrm{min}$, whereas the bath volume was $12.0 \mathrm{ml}$. The organ bath was positioned on the stage of an inverted microscope (Leica, Wetzlar, Germany), where pictures of the arteries were taken by a digital camera (Leica DFC 320). Pictures were analyzed offline (Leica Qwin), where inner and outer diameters were measured. Calibration was made using a micrometer etalon (Wild, Heelbrugg, Switzerland). All chemicals (acetylcholine chloride, L-norepinephrine hydrochloride, nitro-L-arginine methyl ester hydrochloride (L-NAME), bradykinin acetate (purity of all chemicals over 98\%) and quercetin hydrate (purity over $95 \%$ )) were purchased from Sigma-Aldrich, Budapest, Hungary.

\section{Ex vivo protocols}

To study the biomechanical properties of coronary resistance artery segments, two protocols were used. In the first series of experiments, arteries from 12 quercetin-treated animals and 10 control rats were taken and incubated in nKR solution at $50 \mathrm{~mm} \mathrm{Hg}$ intraluminal pressure for $30 \mathrm{~min}$. Arteries develop 
spontaneous tone under these conditions. A pressure diameter curve was next determined by raising the pressure from 10 to $100 \mathrm{~mm} \mathrm{Hg}$ in $10 \mathrm{~mm} \mathrm{Hg}$ steps with a 3-min incubation at each pressure. After a 10-min rest the original diameter was restored, and we added norepinephrine to the bath (final concentration $10 \mu \mathrm{mol} / \mathrm{l})$, incubated the vessel for $10 \mathrm{~min}$ and pressure diameter curves were repeatedly recorded. Without washout, we added $10 \mu \mathrm{mol} / \mathrm{l}$ acetylcholine, incubated for $10 \mathrm{~min}$, and repeated the pressure diameter curve. $100 \mu \mathrm{mol} / 1$ L-NAME was next added to block NO synthesis. After $20 \mathrm{~min}$ of incubation, a pressure diameter curve was taken again. To test reproducibility, a washout with nKR solution was made, followed by incubation for $20 \mathrm{~min}$. Vessels with spontaneous tone differing from the original by more than $5 \%$ at this point were rejected. Finally, the superfusion was changed to $\mathrm{Ca}^{2+}$-free Krebs-Ringer solution (composition in mmol/l: $\mathrm{NaCl} 92, \mathrm{KCl} 4.7, \mathrm{NaH}_{2} \mathrm{PO}_{4} 1.18, \mathrm{MgCl}_{2} 20, \mathrm{MgSO}_{4} 1.17$, $\mathrm{NaHCO}_{3} 24$, glucose 5.5, EGTA 2, and EDTA 0.025), and after $20 \mathrm{~min}$ of incubation the passive pressure diameter curve was recorded.

In the second series, we investigated the properties of artery segments from 10 animals from both groups. The protocol started with a $30-$ min incubation at $50 \mathrm{~mm} \mathrm{Hg}$ in nKR solution, and a pressure diameter curve was next taken as described earlier. After a 10-min rest, bradykinin was added to the bath in a concentration of $1 \mu \mathrm{mol} / 1$, and arterioles were incubated for $10 \mathrm{~min}$ before the pressure diameter curve was repeated. Bradykinin was then washed out, the original tone was checked, and L-NAME was added in $100 \mu \mathrm{mol} / 1$ concentration. The incubation time was $20 \mathrm{~min}$, similarly to the first protocol, and pressure diameter curves were taken again. Reproducibility was tested by measuring spontaneous tone in $\mathrm{nKR}$ solution at $50 \mathrm{~mm} \mathrm{Hg}$; the superfusion was next changed to $\mathrm{Ca}^{2+}$-free Krebs-Ringer, and the passive curve was recorded.

\section{Calculation formulas}

$\mathrm{D}_{\mathrm{i} \text { actual }}$ is the inner diameter in $\mu \mathrm{m}$ at the actual pressure and in solution. $\mathrm{D}_{\mathrm{i}}$ passive is the inner diameter $(\mu \mathrm{m})$ measured in $\mathrm{Ca}^{2+}$-free Krebs-Ringer solution at the given pressure.

Actual diameters were normalized for the passive conditions at each pressure level $\left(\%\right.$ of $\mathrm{Ca}^{2+}$-free $=$ $\left.\left(\mathrm{D}_{\mathrm{i} \text { actual }} * 100\right) / \mathrm{D}_{\mathrm{i} \text { passive }}\right)$. Spontaneous tone was calculated as percentage of $\mathrm{Ca}^{2+}$-free diameter (spontaneous tone $(\%)=100$-inner diameter $\left(\%\right.$ of $\mathrm{Ca}^{2+}$-free $\left.)\right)$. Calculation of wall stress was based on the Laplace-Frank equation $\left(\sigma=\left(P_{t} * r_{i}\right) / h\right)$, where $P_{t}$ is the transmural pressure (in this case, the intraluminal pressure), $r_{i}$ is the inner radius in $\mu \mathrm{m}$, and $\mathrm{h}$ is wall thickness in $\mu \mathrm{m}$. Calculation of incremental elastic modulus was based on Cox's formula (Cox 1979) $\left(\mathrm{E}_{\text {inc }}(\mathrm{kPa})=\left[\left(2 \mathrm{r}_{\mathrm{i}}^{2} * \mathrm{r}_{\mathrm{o}}\right) * \Delta \mathrm{P}\right] /\left[\left(\mathrm{r}_{\mathrm{o}}{ }^{2}-\mathrm{r}_{\mathrm{i}}{ }^{2}\right) *\left(\mathrm{r}_{20}-\mathrm{r}_{10}\right)\right]\right)$, where $\mathrm{r}_{\mathrm{i}}$ is the inner radius in $\mu \mathrm{m}$ at lower pressure, $r_{o}$ is the outer radius in $\mu \mathrm{m}$ at lower pressure, $\Delta \mathrm{P}$ is the increase in pressure (in this case $\Delta \mathrm{P}=10 \mathrm{~mm} \mathrm{Hg}=1.33 \mathrm{kPa}), \mathrm{r}_{20}$ is the outer radius at higher pressure and $r_{10}$ is the outer radius at lower pressure.

\section{Statistical analysis and data presentation}

Data recording and calculations were made with Microsoft Excel. Statistical analysis was performed with GraphPad Prism 6. Values are expressed as mean, with the standard error of mean included. Normal distribution of datasets was checked with Shapiro-Wilk test. Statistical comparisons were made using one or two-way ANOVA with Bonferrroni post hoc test, and linear regression. Statistically significant differences were accepted with $\mathrm{p}$ values less than 0.05 .

\section{Results}

Both groups were healthy, the behavior, alertness, movement, hair or body position of the animals did not show any difference. The average body weight at the beginning of the treatment was $194 \pm 4 \mathrm{~g}$. After 8 weeks, no difference was found either in body weights $(507 \pm 9$ g, vs. $504 \pm 10 \mathrm{~g})$ or heart weights $(1.38 \pm 0.14 \mathrm{~g}$ vs. $1.35 \pm 0.18 \mathrm{~g}$ ) between the control and quercetinsupplemented groups, respectively.

As described in Methods, coronary resistance arteries with close to identical outer diameters during preparation have been selected. Figure 1A shows that there was no difference in fully relaxed inner diameters measured in $\mathrm{Ca}^{2+}$-free solutions (passive diameter). The passive incremental elastic moduli did not differ either (Fig. 1B). However, inner diameters in oxygenized $37^{\circ} \mathrm{C}$ warm Krebs-Ringer solution were significantly smaller in quercetin-treated animals (Fig. 2A) as a result of elevated spontaneous myogenic tone, characteristic for intramural coronary arterioles (Fig. $2 \mathrm{~B}, \mathrm{p}<0.01$ ). This also resulted in a thicker vascular wall under active conditions (Fig. 2C). Under passive conditions, wall thicknesses and relaxed diameters were practically identical (Fig. 2D, $\mathrm{p}<0.01)$. In turn, this increase in vessel wall thickness resulted in decreased tangential wall stress in quercetin- 
A

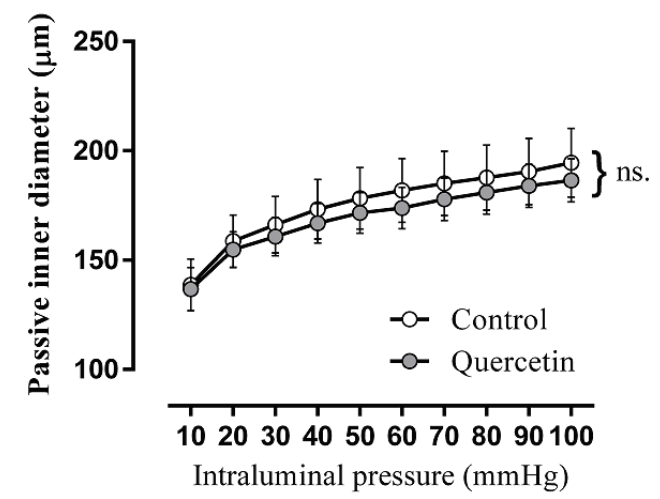

B

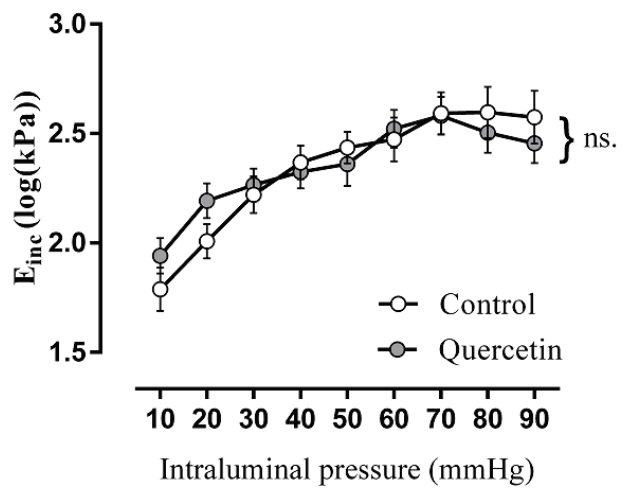

Fig. 1. Passive biomechanical properties. A. Passive inner diameter of coronary arterioles at different intraluminal pressures. There is no statistically significant difference between the two groups in passive lumen geometry with two-way ANOVA. Result of both protocols $(n=22$ quercetin-treated and $n=20$ control). B. Incremental elastic modulus of passive segments as a function of intraluminal pressure. There is no significant difference in passive elasticity between the two groups (Two-way ANOVA, $n=22$ quercetin-treated and $\mathrm{n}=20$ control).

A
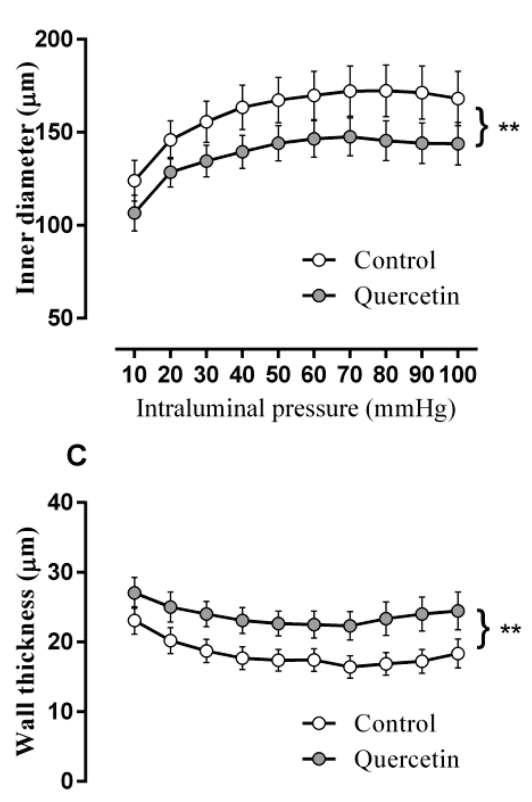

102030405060708090100 Intraluminal pressure $(\mathrm{mmHg})$
B
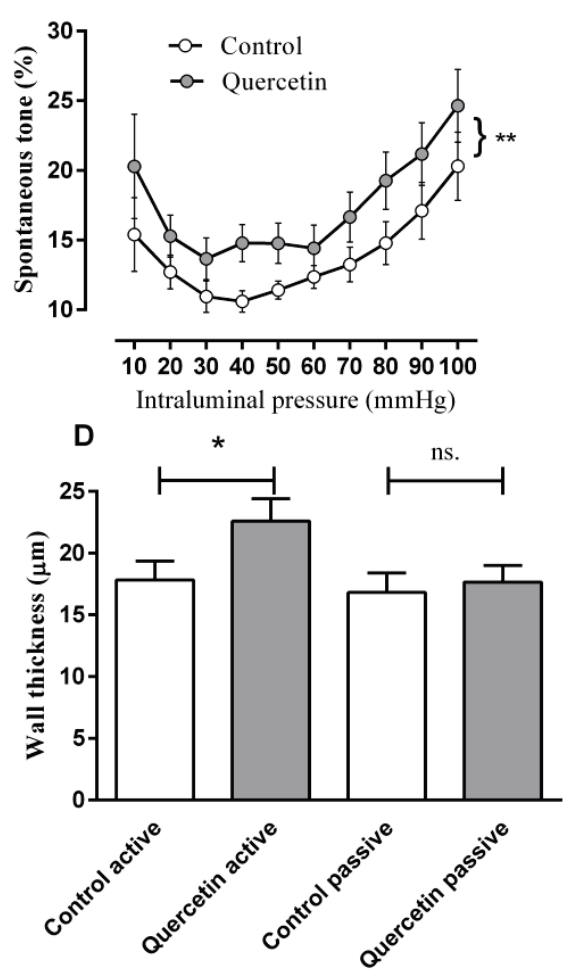

Fig. 2. Active biomechanical properties. A. Pressure diameter curves of coronary segments from control and quercetintreated groups in oxygenized nKR solution (segments in spontaneous and myogenic tone). Note that segments from the quercetin-treated group developed higher spontaneous tone, and thus had decreased inner diameter under active conditions (Two way ANOVA, $\mathrm{p}<0.01 ; \mathrm{n}=22$ quercetintreated and $n=20$ control). B. Spontaneous and myogenic tone developed in nKR in response to stepwise elevation of intraluminal pressure. Note that the quercetin-treated group had increased spontaneous tone. Data expressed in percent of passive diameter (Two-way ANOVA, $p<0.01 ; n=22$ quercetin-treated and $n=20$ control). C. Wall thickness under active conditions, measured in nKR solution. In parallel with the higher tone, the vessel wall was thickened (Two-way ANOVA, $\mathrm{p}<0.01 ; \mathrm{n}=22$ quercetin-treated and $\mathrm{n}=20$ control). D. Comparison of wall thicknesses at $50 \mathrm{~mm} \mathrm{Hg}$ intraluminal pressure in passive and spontaneously contracted arteries, revealing remodeling of the wall under active conditions (One-way ANOVA, $\mathrm{p}<0.05 ; \mathrm{n}=22$ quercetin-treated and $\mathrm{n}=20$ control). E. Tangential wall stress under active conditions (in nKR solution). Note reduced wall stress in the arteries of quercetin-treated animals (Two-way ANOVA, $\mathrm{p}<0.01 ; \mathrm{n}=22$ quercetin-treated and $n=20$ control). 
treated animals under active conditions (Fig. 2E, $\mathrm{p}<0.01$ ). Applying linear regression we found significant difference between slopes ( $95 \%$ confidence intervals: control 0.3896 to 0.4821 , quercetin treated 0.3163 to $0.3865, \mathrm{p}=0.004$ ).

We found a slight but significant reduction in vasodilatory response to $10 \mu \mathrm{mol} / 1$ norepinephrine in the range of 10 to $80 \mathrm{~mm} \mathrm{Hg} \mathrm{(p=0.01,} \mathrm{Fig.} \mathrm{3)} \mathrm{in} \mathrm{quercetin-}$ treated animals. Dilation rather than constriction is the typical response to norepinephrine in resistance-sized coronary arterioles (Ming et al. 1997). At the same time, acetylcholine $(10 \mu \mathrm{mol} / \mathrm{l})$ and bradykinin $(1 \mu \mathrm{mol} / \mathrm{l})$ induced dilation have also been somewhat reduced (Figs 4A and 4B). However, administration of L-NAME $(100 \mu \mathrm{mol} / \mathrm{l})$ induced much more forceful contractions in quercetin-supplemented animals, revealing that basal NO-dependent vasodilation was much higher in them (between $60-100 \mathrm{~mm} \mathrm{Hg}, \mathrm{p}<0.03$, Fig. 4C). Figure 4D reveals that while there is no difference in maximum endothelial dilation capacity, a higher part of this capacity is used under basal conditions in quercetin-supplemented animals' vessels.

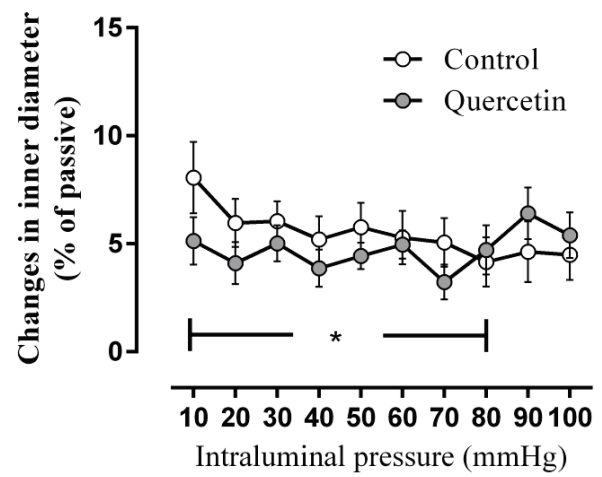

Fig. 3. Dilation induced by $10 \mu \mathrm{mol} / \mathrm{l}$ norepinephrine (as compared to segments in myogenic tone in nKR solution). See the reduced beta adrenergic dilation of quercetin-treated segments. Statistically significant between $10-80 \mathrm{~mm} \mathrm{Hg}$ intraluminal pressure (Two-way ANOVA $p<0.01$ ).

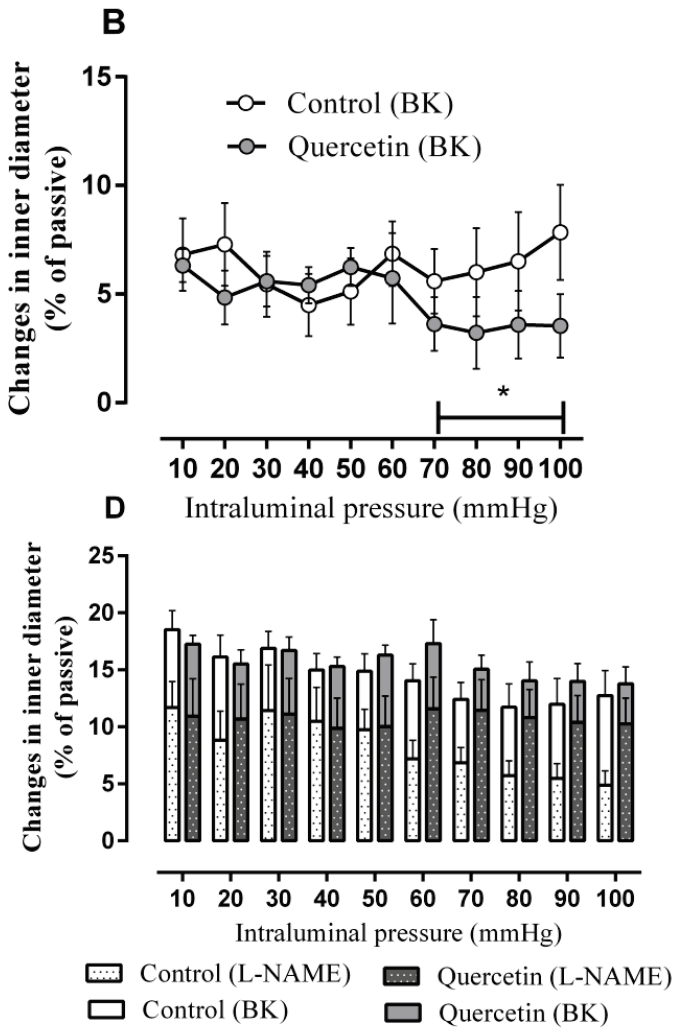

Fig. 4. NO-mediated dilation. A. Vasodilatation of spontaneously contracted segments induced by $10 \mu \mathrm{mol} / \mathrm{l}$ acetylcholine. Note reduced acetylcholine dilation in the pressure range of $30-60 \mathrm{~mm} \mathrm{Hg}$ (Two-way ANOVA $\mathrm{p}<0.01$ ). B. Vasodilatation of spontaneously contracted segments induced by $1 \mu \mathrm{mol} / \mathrm{l}$ bradykinin. Note reduced bradykinin-stimulated dilation in the pressure range of $70-100 \mathrm{~mm} \mathrm{Hg}$ (Two-way ANOVA p <0.01). C. Additional vasoconstriction induced in spontaneously contracted segments by application of the NO synthase blocker L-NAME $(100 \mu \mathrm{mol} / \mathrm{l})$. Note higher level of basal NO dilation of quercetin-treated segments. Significant between $60-100 \mathrm{~mm} \mathrm{Hg}$ intraluminal pressure (Two-way ANOVA, $\mathrm{p}<0.05 ; \mathrm{n}=10$ quercetin treated, $\mathrm{n}=10$ control, data from second series of experiment). D. Sum of basal and bradykinin-induced endothelial vasodilation. Basal NO-mediated dilatation is measured with application of L-NAME (bars with pattern). In control vessels this dilator effect is decreasing as a function of increasing intraluminal pressure, while in quercetin-treated vessels basal NO-mediated dilation is constant. Bradykinin induced endothelial vasodilation (bars without pattern) is a reserve of NO-mediated vasodilation. Note that maximum NO-induced vasodilation (sum of basal and induced NO-mediated dilation) did not differ between the two groups, whereas quercetin-treated segments showed higher basal NO dilation activity using up a higher portion of that maximum capacity under basal conditions. 


\section{Discussion}

In this study we identified the effects of a $30 \mathrm{mg} / \mathrm{kg} /$ day supplementary dose of quercetin compared to those of the routine quercetin intake with standard rat chow, on the passive and active biomechanical properties, and on some of the pharmacological responsiveness of intramural coronary arterioles of the rat. Passive properties such as wall thickness and passive elasticity did not change due to quercetin supplementation for eight weeks in comparison with the control. However, characteristic remodeling of the active biomechanical and the pharmacological properties could be observed. Spontaneous tone increased and caused reduced lumen and increased vascular wall thickness in spontaneously contracted arteries, ensuring a higher dilatation reserve for these arteries. In parallel with this, a significantly elevated basal endothelial dilation of the arteries from quercetin-supplemented animals was found.

In an earlier report, quercetin supplementation resulted in improvement of wall elasticity in abdominal aortas denuded by a balloon catheter (Huang et al. 2009). No change in passive segmental geometry or passive elastic properties was found in our experiment on coronary arterioles. This can be explained by the use of a lower amount of quercetin in our studies. We applied a $30 \mathrm{mg} / \mathrm{kg}$ daily dose in contrast to the evidently pharmacological doses of $100 \mathrm{mg} / \mathrm{kg}$ and $200 \mathrm{mg} / \mathrm{kg}$ used by the above cited authors. This dose of $30 \mathrm{mg} / \mathrm{kg} /$ day in rats is thought to be comparable with $5 \mathrm{mg} / \mathrm{kg} /$ day in humans (Reagan-Shaw et al. 2008), a dose commonly advised for human nutrition studies (McAnulty et al. 2013, Perez et al. 2014). Furthermore, we must not forget that our studies were made in otherwise healthy vessels, not on pathologic large artery specimens.

Increased myogenic tone is one of our key observations. It can be the result of altered calcium homeostasis in smooth muscle cells by quercetin acting as an activator of L-type $\mathrm{Ca}^{2+}$ channels (Saponara et al. 2002), and also having a biphasic effect on $\mathrm{Ca}^{2+}$ ATP-ase (McKenna et al. 1996). The tone elevation we observed may have two consequences. First, in situ lumen size decreases. That means that despite the identity of passive vessel characteristics, the position in the coronary network of the quercetin-treated artery segments we prepared was different from that of the control artery segments with the same passive diameter. For example, at $70 \mathrm{~mm} \mathrm{Hg}$ intraluminal pressure the inner diameter of treated arteries was $147 \pm 10 \mu \mathrm{m}$, whereas that of the untreated ones was $172 \pm 13 \mu \mathrm{m}(\mathrm{p}<0.05$ with Bonferroni post hoc test). This difference means that upon full relaxation (supposing other parameters are unchanged) there is a $75.2 \%$ elevation in flow in the control, and a $101.6 \%$ elevation in blood flow in quercetin-treated arteries (computation based on the Poiseuille law). We can declare that the quercetin-treated arteries had a much higher dilatation reserve for coronary vasomotion. The second difference concerns in situ wall thickness. At $70 \mathrm{~mm} \mathrm{Hg}$ intraluminal pressure arteries in spontaneous contraction had a wall thickness of $16.4 \pm 1.6 \mu \mathrm{m}$, whereas in quercetin-treated arteries $22.3 \pm 2.0 \mu \mathrm{m}$ wall thickness was observed. These values correspond to tangential wall stresses of $30.9 \pm 2.5 \mathrm{kPa}$ in control vessels, and to $24.5 \pm 1.8 \mathrm{kPa}$ in quercetin-treated arteries at $70 \mathrm{~mm} \mathrm{Hg}$ intraluminal pressure under spontaneous myogenic tone $(p<0.05)$. There is good reason to assume that quercetintreated arteries function at much lower wall stresses than control ones in vivo.

Type $\beta 2$ adrenergic receptors prevail on smooth muscle cells of resistance-sized coronary arteries; the direct effect of norepinephrine on these vessels is relaxation (Ming et al. 1997). In our experiments, both control and quercetin-treated arteries are relaxed by norepinephrine, the latter group producing less extensive relaxation. This is in good agreement with recent observations, according to which quercetin, its glucosides and its 3-glucuronide metabolite inhibit the activity of the enzyme adenylyl cyclase (Yamazaki et al. 2014, Pavan et al. 2015). After oral administration quercetin is metabolized to sulphates and glucuronides by the liver both in humans (Ishizawa et al. 2011) and in the rat (Omar et al. 2014). A $\beta$-glucuronidase can cleave quercetin from the metabolite in the vessel wall (PerezVizcaino et al. 2012), thus these compounds can affect adenylyl cyclase, causing limited relaxation. Interestingly, recent studies indicate the hemodynamic effect of 3-(3-hydroxyphenyl)propionic acid, produced by the human colon microflora from quercetin (Najmanová et al. 2016).

One important observation of our experiments was that chronic supplementation of quercetin enhanced NO-mediated dilation as shown by the L-NAME contractions, especially at higher intraluminal pressures. Because quercetin supplementation does not increase eNOS expression in healthy rodents (Takahashi et al. 2015, Wan et al. 2009), this could be the consequence of two mechanisms. First, quercetin induces rapid 
phosphorylation of eNOS at serine 1179 , which in turn increases the activity of the enzyme ( $\mathrm{Li}$ et al. 2012). Another mechanism can be an enhanced $\mathrm{Ca}^{2+}$-entry into endothelial cells and consequent elevated NO production involving large conductance $\mathrm{Ca}^{2+}$-activated $\mathrm{K}^{+}$channels (BK(Ca) channels) (Kuhlmann et al. 2005). As it is summarized in Figure 4D, the higher basal NO release of supplemented arteries (L-NAME effect) could not be further increased by eNOS activators (Ach, BK), and this explains the reduced effect of these substances shown in Figures 4A and 4B. Direct measurements on smooth muscle cell calcium homeostasis and endothelial expression of eNOS were not made. These conclusions are based on literature, because of available data in published studies.

Some limitation of our study seems to be the precise dosage of quercetin. Taking into consideration of the long animal treatment period, we choose the safer dosage by drinking water instead of gavage. In both groups, 3 animals were kept in a cage to minimize nonspecific stress. With standardizing the environment, we ensured standard and average water consumption during treatment, which provided a fairly standardized quercetin intake.

In conclusion, chronic administration of quercetin to rats in dietetically real amounts induces a structural and functional remodeling of resistance coronary artery segments, including reduced elastic stress of the vessel wall, increased dilatory reserve, and augmented NO-mediated endothelial dilation. Quercetintreatment results in a substantially higher (30\%) spontaneous tone. The enhanced basal NO-mediated dilation and higher spontaneous tone together may provide a new balance point of vasodilatory and vasoconstrictor mechanisms. Although polyphenols are not vitamins (Vickery et al. 1950), long-term quercetin intake may result in wider adaptation range and lower elastic stress for coronary arteries.

\section{Conflict of Interest}

There is no conflict of interest.

\section{Acknowledgement}

Expert technical assistance of Ms Ildiko Oravecz is appreciated. The study was supported by Hungarian National grant OTKA TO 32019 and K-112964, by the Hungarian Hypertension Society and the Hungarian Kidney Foundation. The Hungarian Ministry of Human Resources provided a PhD stipend for the first author (A. M.-K.).

\section{Abbreviations}

Ach - acetylcholine, BK - bradykinin, $\mathrm{Ca}^{2+}$ free $\mathrm{Ca}^{2+}$-free Krebs-Ringer solution, eNOS - endothelial nitric oxide synthase, L-NAME - nitro-L-arginine methyl ester, nKR - normal Krebs-Ringer solution, NO - nitric oxide, ROS - reactive oxygen species.

\section{References}

COX RH: Comparison of arterial wall mechanics in normotensive and spontaneously hypertensive rats. Am J Physiol 237: H159-H167, 1979.

EDWARDS RL, LYON T, LITWIN SE, RABOVSKY A, SYMONS JD, JALILI T: Quercetin reduces blood pressure in hypertensive subjects. J Nutr 137: 2405-2411, 2007.

GALISTEO M, GARCIA-SAURA MF, JIMENEZ R, VILLAR IC, ZARZUELO A, VARGAS F, DUARTE J: Effects of chronic quercetin treatment on antioxidant defence system and oxidative status of deoxycorticosterone acetate-salt-hypertensive rats. Mol Cell Biochem 259: 91-99, 2004.

HAN JJ, HAO J, KIM CH, HONG JS, AHN HY, LEE YS: Quercetin prevents cardiac hypertrophy induced by pressure overload in rats. $J$ Vet Med Sci 71: 737-743, 2009.

HUANG BF, WANG W, FU YC, ZHOU XH, WANG X: The effect of quercetin on neointima formation in a rat artery balloon injury model. Pathol Res Pract 205: 515-523, 2009.

IBARRA M, MORENO L, VERA R, COGOLLUDO A, DUARTE J, TAMARGO J, PEREZ-VIZCAINO F: Effects of the flavonoid quercetin and its methylated metabolite isorhamnetin in isolated arteries from spontaneously hypertensive rats. Planta Med 69: 995-1000, 2003.

ISHIZAWA K, YOSHIZUMI M, KAWAI Y, TERAO J, KIHIRA Y, IKEDA Y, TOMITA S, MINAKUCHI K, TSUCHIYA K, TAMAKI T: Pharmacology in health food: metabolism of quercetin in vivo and its protective effect against arteriosclerosis. J Pharmacol Sci 115: 466-470, 2011. 
KAWAI Y, SAITO S, NISHIKAWA T, ISHISAKA A, MUROTA K, TERAO J: Different profiles of quercetin metabolites in rat plasma: comparison of two administration methods. Biosci Biotechnol Biochem 73: 517-523, 2009.

KUHLMANN CR, SCHAEFER CA, KOSOK C, ABDALLAH Y, WALTHER S, LUDDERS DW, NEUMANN T, TILLMANNS H, SCHAFER C, PIPER HM, ERDOGAN A: Quercetin-induced induction of the NO/cGMP pathway depends on $\mathrm{Ca}^{2+}$-activated $\mathrm{K}^{+}$channel-induced hyperpolarization-mediated $\mathrm{Ca}^{2+}$-entry into cultured human endothelial cells. Planta Med 71: 520-524, 2005.

LARSON A, WITMAN MA, GUO Y, IVES S, RICHARDSON RS, BRUNO RS, JALILI T, SYMONS JD: Acute, quercetin-induced reductions in blood pressure in hypertensive individuals are not secondary to lower plasma angiotensin-converting enzyme activity or endothelin-1: nitric oxide. Nutr Res 32: 557-564, 2012.

LEE K-H, PARK E, LEE H-J, KIM M-O, CHA Y-J, KIM J-M, LEE H, SHIN M-J: Effects of daily quercetin-rich supplementation on cardiometabolic risks in male smokers. Nutr Res Pract 5: 28-33, 2011.

LI PG, SUN L, HAN X, LING S, GAN WT, XU JW: Quercetin induces rapid eNOS phosphorylation and vasodilation by an Akt-independent and PKA-dependent mechanism. Pharmacology 89: 220-228, 2012.

MCANULTY LS, MILLER LE, HOSICK PA, UTTER AC, QUINDRY JC, MCANULTY SR: Effect of resveratrol and quercetin supplementation on redox status and inflammation after exercise. Appl Physiol Nutr Metab 38: 760-765, 2013.

MCKENNA E, SMITH JS, COLL KE, MAZACK EK, MAYER EJ, ANTANAVAGE J, WIEDMANN RT, JOHNSON RG JR: Dissociation of phospholamban regulation of cardiac sarcoplasmic reticulum $\mathrm{Ca}^{2+}$ ATPase by quercetin. J Biol Chem 271: 24517-24525, 1996.

MING Z, PARENT R, LAVALLEE M: Beta 2-adrenergic dilation of resistance coronary vessels involves $\mathrm{K}_{\mathrm{ATP}}$ channels and nitric oxide in conscious dogs. Circulation 95: 1568-1576, 1997.

MONORI-KISS A, MONOS E, NÁDASY GL: Quantitative analysis of vasodilatory action of quercetin on intramural coronary resistance arteries of the rat in vitro. PLoS One 9: e105587, 2014.

NADASY GL, SZEKERES M, DEZSI L, VARBIRO S, SZEKACS B, MONOS E: Preparation of intramural small coronary artery and arteriole segments and resistance artery networks from the rat heart for microarteriography and for in situ perfusion video mapping. Microvasc Res 61: 282-286, 2001.

NAJMANOVÁ I, POUROVÁ J, VOPRŠALOVÁ M, PILAŘOVÁ V, SEMECKÝ V, NOVÁKOVÁ L, MLADĚNKA P: Flavonoid metabolite 3-(3-hydroxyphenyl)propionic acid formed by human microflora decreases arterial blood pressure in rats. Mol Nutr Food Res 60: 981-991, 2016.

OMAR K, GRANT MH, HENDERSON C, WATSON DG: The complex degradation and metabolism of quercetin in rat hepatocyte incubations. Xenobiotica 44: 1074-1082, 2014.

PAVAN B, CAPUZZO A, FORLANI G: Quercetin and quercetin-3-O-glucoside interact with different components of the cAMP signaling cascade in human retinal pigment epithelial cells. Life Sci 121: 166-173, 2015.

PEREZ A, GONZALEZ-MANZANO S, JIMENEZ R, PEREZ-ABUD R, HARO JM, OSUNA A, SANTOS-BUELGA C, DUARTE J, PEREZ-VIZCAINO F: The flavonoid quercetin induces acute vasodilator effects in healthy volunteers: correlation with beta-glucuronidase activity. Pharmacol Res 89: 11-18, 2014.

PEREZ-VIZCAINO F, DUARTE J, SANTOS-BUELGA C: The flavonoid paradox: conjugation and deconjugation as key steps for the biological activity of flavonoids. J Sci Food Agric 92: 1822-1825, 2012.

REAGAN-SHAW S, NIHAL M, AHMAD N: Dose translation from animal to human studies revisited. FASEB $J$ 22: 659-661, 2008.

SAPONARA S, SGARAGLI G, FUSI F: Quercetin as a novel activator of L-type $\mathrm{Ca}^{2+}$ channels in rat tail artery smooth muscle cells. Br J Pharmacol 135: 1819-1827, 2002.

SCALBERT A, WILLIAMSON G: Dietary intake and bioavailability of polyphenols. $J$ Nutr 130: $2073 \mathrm{~s}-2085 \mathrm{~s}, 2000$.

TAKAHASHI A, INOUE H, MISHIMA K, IDE F, NAKAYAMA R, HASAKA A, RYO K, ITO Y, SAKURAI T, HASEGAWA Y, SAITO I: Evaluation of the effects of quercetin on damaged salivary secretion. PLoS One 10: e0116008, 2015.

VICKERY HB, NELSON EM, ALMQUIST HJ, ELVEHJEM CA: Term "vitamin P" recommended to be discontinued. Science 112: 628, 1950. 
WADE CE, MILLER MM, BAER LA, MORAN MM, STEELE MK, STEIN TP: Body mass, energy intake, and water consumption of rats and humans during space flight. Nutrition 18: 829-836, 2002.

WAN LL, XIA J, YE D, LIU J, CHEN J, WANG G: Effects of quercetin on gene and protein expression of NOX and NOS after myocardial ischemia and reperfusion in rabbit. Cardiovasc Ther 27: 28-33, 2009.

YAMAZAKI S, MIYOSHI N, KAWABATA K, YASUDA M, SHIMOI K: Quercetin-3-O-glucuronide inhibits noradrenaline-promoted invasion of MDA-MB-231 human breast cancer cells by blocking beta(2)-adrenergic signaling. Arch Biochem Biophys 557: 18-27, 2014.

YAN L, ZHANG JD, WANG B, LV YJ, JIANG H, LIU GL, QIAO Y, REN M, GUO XF: Quercetin inhibits left ventricular hypertrophy in spontaneously hypertensive rats and inhibits angiotensin II-induced H9C2 cells hypertrophy by enhancing PPAR- $\gamma$ expression and suppressing AP-1 activity. PLoS One 8: e72548, 2013.

YOO J, KIM Y, YOO S-H, INGLETT GE, LEE S: Reduction of rutin loss in buckwheat noodles and their physicochemical characterisation. Food Chem 132: 2107-2111, 2012. 